\title{
Ultrastructural Circuitry in Retinal Cell Transplants to Rat Retina
}

\author{
Charles L. Zucker*, Berndt Ehinger ${ }^{+}$, Magdalene Seiler ${ }^{*}$, Robert B. Aramant ${ }^{*}$ and Alan R. Adolph* \\ *The Schepens Eye Research Institute and Harvard Medical School, Boston, MA, USA \\ ${ }^{+}$Department of Ophthalmology, University of Lund, Lund, Sweden \\ \$Present address: Department of Ophthalmology \& Visual Sciences and Department of Anatomical Sciences \\ \& Neurobiology, University of Louisville Medical School, Louisville, KY, USA
}

\section{SUMMARY}

The development of five transplants of fetal retinal tissue to adult rat eyes was examined with the electron microscope. The transplants were of 9 to 10 weeks total age after conception in four cases and 20 weeks in one case. They were at stage E15 when transplanted. Transplants developed in both the epiretinal and subretinal spaces.

The transplants were heterogeneously developed with some parts showing almost normal differentiation and others little. Subretinal transplants examined in this study were more developed than epiretinal grafts. Photoreceptor cells developed both inner and outer segments. Their synaptic terminals possessed output ribbon synapses with postsynaptic processes similar to those seen in normal retinas. In regions corresponding to the inner plexiform layer, the adult complement of synapses was seen, including advanced features such as serial synapses as well as reciprocal synapses at bipolar cell dyads. Incompletely differentiated synapses of both the amacrine and bipolar cell types were often observed, especially in the rat epiretinal transplants. Ganglion cell processes could not be identified with certainty.

Although transplant cells were adjacent to host photoreceptor cells and pigment epithelium, obvious specializations or interactions were not observed. The experiments

\footnotetext{
Reprint address:

Dr. Berndt Ehinger

Department of Ophthalmology

Lund University Hospital

S-221 85 Lund

Sweden
}

suggest that embryonic rat retinal cell transplants develop most or perhaps all of the structural components and neuronal circuitry necessary to transduce light and process some visual information.

\section{KEY WORDS}

retinal cell transplants, retinal fetal cells, synapses, rat, electron microscopy

\section{INTRODUCTION}

Cells of immature neural retina have been shown to survive and differentiate when transplanted to adult retina in a few mammalian species $/ 6,9,11$ $16,20-22,26-28,30-33 /$, and xenografts have similarly been successful (mouse to rat, fetal human retinal cells to adult rat retina) $/ 5,7,17 /$. Transplantation of mature retinal cells has also been reported $/ 30,31 /$. However, there are only a few reports on the ultrastructure of the transplants, and none that exclusively deals with the electron microscopy of rat to rat transplants, which initiated the work reported here.

Transplantation of embryonic retinal cells offers an interesting model for studies on factors governing the differentiation of central nervous system neurons. Provided that the neurons in the transplants form a reasonably normal synaptic network with each other, there may also be a clinical use for retinal cell transplants. To establish the extent to which the transplants form the type of synapses and the architecture seen in normal development, we have examined the ultrastructure of transplants of fetal rat retina to adult rat retina. The transplants were studied at 7 to 8 weeks after 
implantation (four eyes) and, in two eyes, at 19 weeks. The rat retina is fully differentiated 3 weeks postnatally, which would correspond to a transplant age of 4 weeks. It has been shown with cell markers for glial cells $/ 29 /$ and for neurons /4/ that rat embryonic transplants develop according to their intrinsic timetable. All synaptic types seen in normal retinas were found in the transplants, including gap junctions which have not previously been seen in transplants. The results reported here have previously been presented in preliminary form $/ 19,37,38 /$

\section{MATERIALS AND METHODS}

Transplantations were performed in rats using the methods described earlier $/ 6,33 /$. Briefly, the fetal retinas were dissected from the surrounding tissues in sterile phosphate buffered saline, which was also used as the injection vehicle. Adult female albino Sprague-Dawley rats received unilateral retinal grafts by injecting $0.5-1 \mu$ of embryonic tissue into a small lesion made by cutting through sclera, choroid, and retina 1-2 $\mathrm{mm}$ behind the equator $15 /$. Pieces of peripheral and central donor retina were randomly mixed in the transplants.

Transplants from six eyes were examined with the electron microscope, four from transplants taken 8 weeks after the transplantation and two taken 19 weeks after the transplantation. All were transplanted at stages E13-E15. Pigment epithelium was not included. Three transplants were epiretinal, one was subretinal and two were both epi- and subretinal. We define an epiretinal transplant as one sitting on the vitreal surface of the retina and a subretinal transplant as one located between the photoreceptors and the pigment epithelium, i.e. in the space formed under the neuroretina when it detaches from the pigment epithelium. From a strict ontogenetic point of view, this is an intraretinal site, but we feel the term "subretinal" more appropriately describes the location of the transplant than terms like "intraretinal" or "paraphotoreceptoral" would. The retinas of two sham-operated animals were also examined by light microscopy two weeks after surgery. They did not show any structures that could be confused with transplanted tissue.

For both light and electron microscopy, retinas were fixed with $1.6 \%$ glutaraldehyde plus $1 \%$ freshly prepared formaldehyde in $0.1 \mathrm{M}$ sodium phosphate buffer containing $0.15 \mathrm{mM} \mathrm{CaCl}, \mathrm{pH}$ 7.35 for one hour at room temperature, followed by overnight at $4^{\circ} \mathrm{C}$. The tissue was then washed, postfixed for one hour with $2 \% \mathrm{OsO}_{4}$, dehydrated through a graded series of ethanol and embedded in epon. $1 \mu \mathrm{m}$ sections were cut with a glass knife for light microscopy and stained with a mixture of methylene blue and toluidine blue. For electron microscopy, $80 \mathrm{~nm}$ silver sections were cut with a diamond knife, counterstained with both uranyl acetate and lead citrate and examined with both a Philips 410 and a JEOL 100CX electron microscope, each operated at $80 \mathrm{kV}$.

\section{RESULTS}

\section{Light microscopy}

With the light microscope, different regions of the transplants resembled the normal layers in the adult retina. The degree of differentiation was assessed from the diversity of cell types (as determined by cell body size and the density of cytoplasmic and nuclear staining) and the proportion of laminated regions in the transplant, rosettes included (see below). Subretinal grafts were generally better differentiated than epiretinal grafts. The description given here is based on subretinal grafts, and differences between the two types will be noted separately.

The grafts were composed of cell layers organized into rosettes with photoreceptor cells oriented toward the rosette lumen (Figure 1), as previously described $/ 5 /$. A rosette is composed of a lumen surrounded by an innermost shell of photoreceptor cells and, to varying degrees, by other retinal layers. An outer limiting membrane (i.e. a zone of junctions between the cells) at the level of the photoreceptor cells was also usually seen. Photoreceptors were seen to form the most central cell layer of the rosettes. Often, a concentric neuropil similar to an outer plexiform layer was seen surrounding the photoreceptor cell bodies. The space between rosettes was usually filled with cells similar to those of the inner nuclear layer and with neuropil regions resembling the inner plexiform layer. We did not find it effective to use the 
morphology of the cell bodies to distinguish different cell types in this region. On occasion, regions containing only poorly differentiated cells were also found interspersed amongst the relatively well differentiated regions. There was no obvious ganglion cell layer, nor was there any well organized inner limiting membrane. Although polarized toward rosette centers, layering was usually seen reminiscent of that of the normal retina (Figure 1b).

In contrast to the normal appearance of the host retina peripheral to the graft, host photoreceptor cells showed varying degrees of degeneration where the graft separated these cells from the pigment epithelium. No cellular infiltration or other signs of inflammation were seen in either the host or transplant.

\section{Electron microscopy}

Electron microscopy confirmed that graft regions which in the light microscope resembled normal retinas usually contained the cellular and synaptic components expected in a normal retina. Projecting into the rosette lumens, photoreceptor outer and inner segments with connecting cilia and basal bodies were common, often distorted, but at times only moderately so (Figure 2). Müller glia microvilli often projected into the center of the rosettes (Figure 3a), at times so abundantly that the center of the rosette appeared to consist of microvilli only (Figure 3b). Macrophage-like cells with dense nuclei and an abundance of lysosomelike organelles were observed in the center of the rosettes with moderate frequency.

The photoreceptor synaptic terminals were either clustered or aligned with each other, frequently containing one or several synaptic ribbons with postsynaptic processes arranged in a dyadic or triadic configuration. The triads often contained processes resembling both horizontal and bipolar cell types in well developed parts of the transplants (Figure 4). Numerous synaptic vesicles filled the photoreceptor terminals, and synaptic ribbons were prominent at the invaginations. A presynaptic arciform density was commonly present, and both the pre- and postsynaptic membranes showed increased electron density as is typical in fully developed photoreceptor synapses.

Some regions, especially within epiretinal grafts, were less well developed, with many of the photoreceptor terminals showing poorly defined structural features. Occasionally, synaptic ribbons were found within photoreceptor terminals without any direct association with the cell membrane or any postsynaptic processes (Figure $4 \mathrm{~b}$ ).

Regions corresponding to the inner plexiform layer exhibited a relatively high synaptic density which was consistent from region to region (Figure 5). Most, but not all synaptic terminals contained conventional synaptic vesicles. Occasionally, small and large dense-cored vesicles could be seen (Figure 6). Synapses of the conventional type (thought to represent amacrine cell synapses) were relatively common (Figure 7a). Amacrine-toamacrine synapses were common, sometimes in both serial and reciprocal configurations (Figure 7b). Amacrine cell processes also made contacts with, and received input from, bipolar cell processes (Figure 7c). The identity of some photoreceptor cell processes could not be positively determined. Occasional amacrine cell synapses onto small dendritic spines or thin intervaricose processes were seen.

Bipolar cell processes in the inner plexiform layer are characterized by their high density of synaptic vesicles and ribbon synapses with the postsynaptic processes arranged in dyads. Such synaptic arrangements were often observed within inner plexiform regions of the grafts. Most often the two postsynaptic elements were amacrine cell processes (Figure 8a), but in a quarter to a fifth of the cases, one was a clear-cut amacrine cell process whereas the other was conspicuously different, with microtubules but no synaptic vesicles or any other characteristic amacrine cell marker (Figure 8b). These features are also typical of the postsynaptic elements at bipolar cell synapses found in normal retinas. Monadic ribbon synapses with only one postsynaptic element (Figure 8c), and bipolar cell processes with synaptic ribbons not directly associated with the cell membrane were infrequently present (Figure 8d).

Electrical gap junctions have been identified between amacrine cell processes as well as amacrine cell processes and amacrine cell bodies (Figure 9a). 

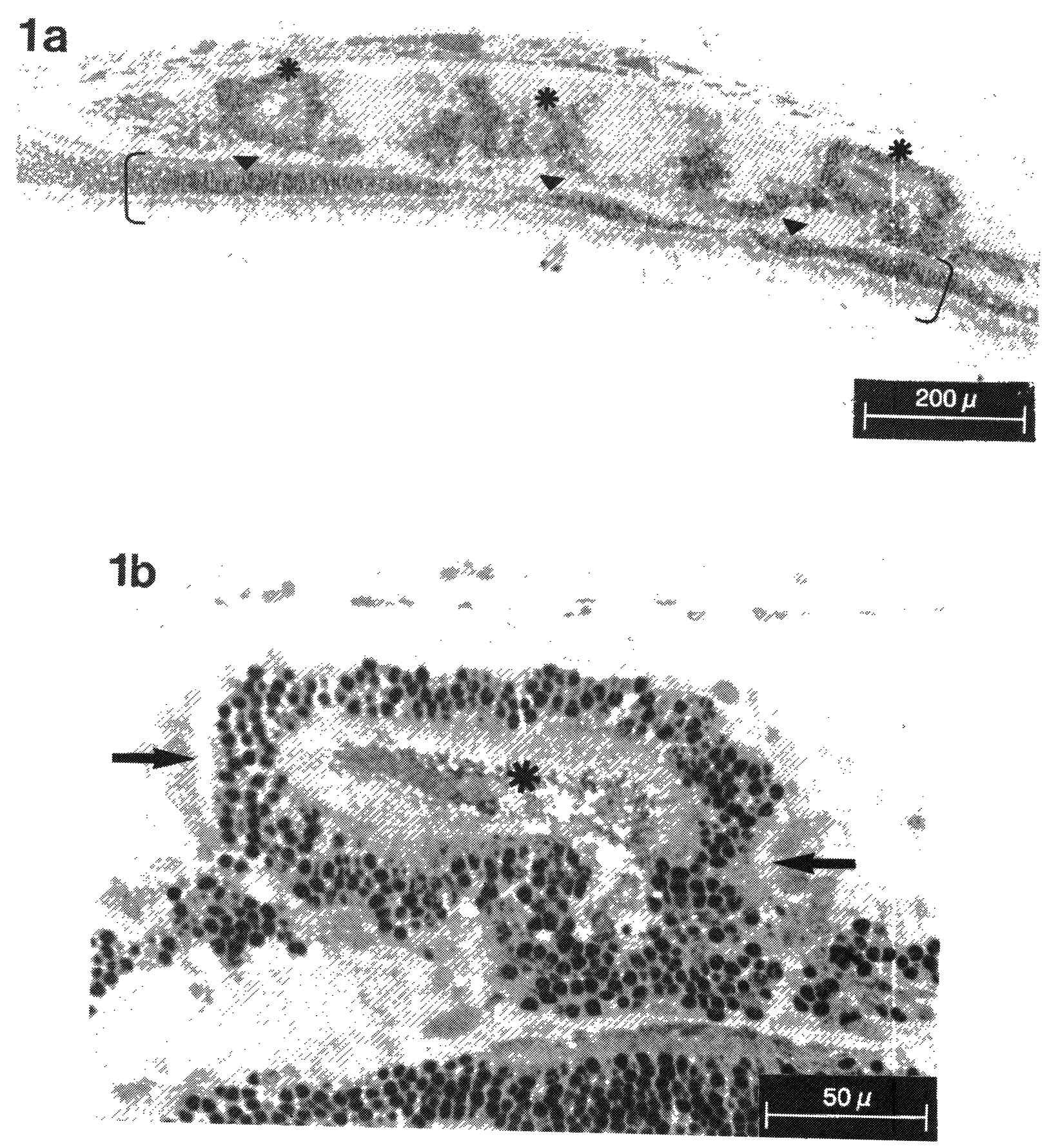

Fig. 1: Light micrographs of a rat-to-rat subretinal transplant. (a) At low magnification, the general relationship between the graft and the host retinas is apparent. Prominent rosettes (*) are separated by regions of neuropil. Such subretinal grafts can be clearly distinguished from the overlying host retina (nuclear layers: [ ]) which maintains a relatively extensive outer nuclear layer $(\boldsymbol{V})$. (b) At higher magnification, the subretinal graft is seen to contain most of the nuclear and plexiform layering typical of normal retinas. Photoreceptor outer segments appear within the rosette core $(*)$. Between this outer nuclear layer and another nuclear layer, which resembles the inner nuclear layer, is an outer plexiform layer $(\rightarrow)$. Extensive inner plexiform-type regions are apparent between the rosetted layers. 


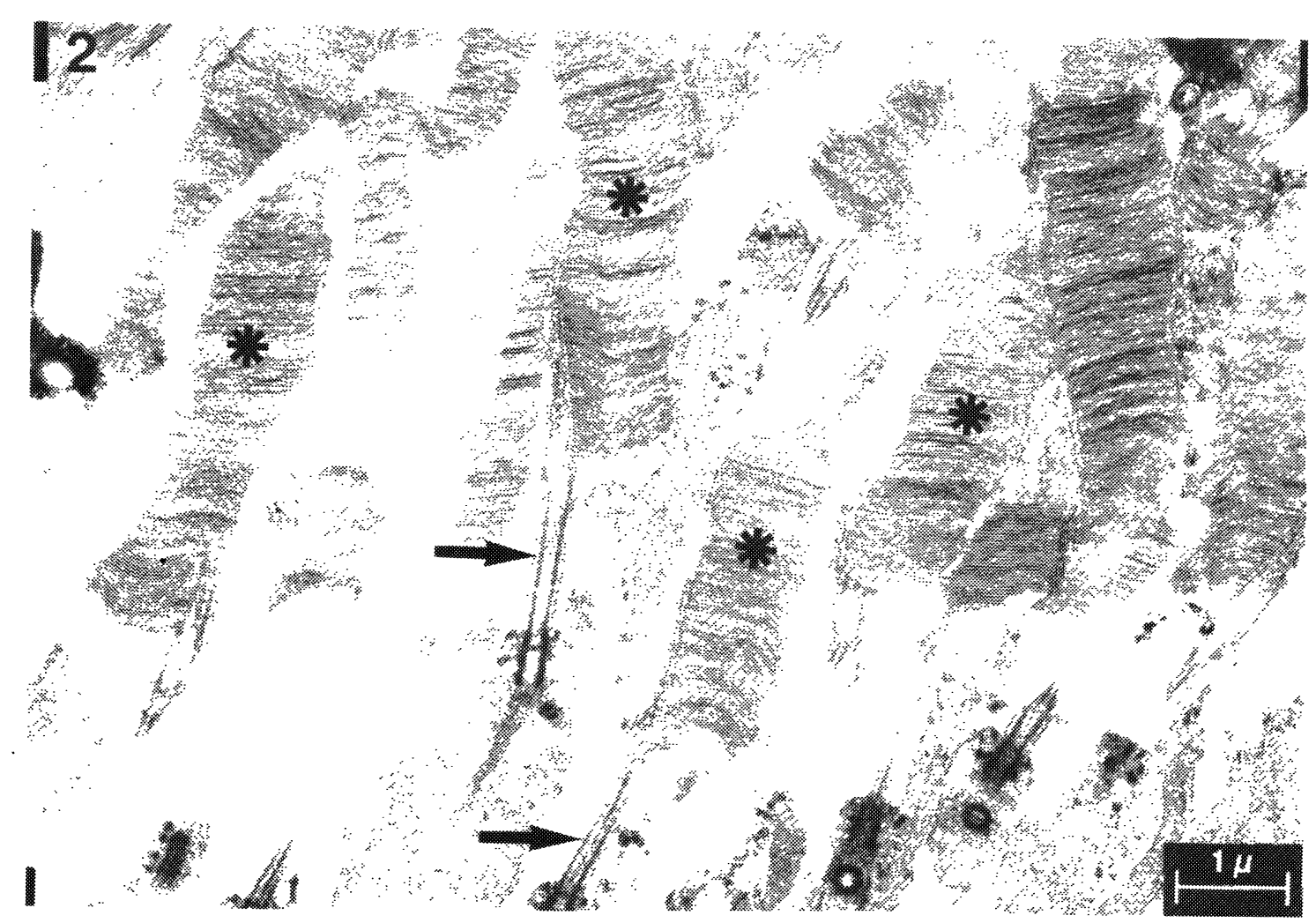

Fig. 2: Electron micrograph showing both inner and outer segments within a rosette core from a rat-to-rat retinal graft. Well oriented stacks of outer segment discs (*), as well as prominent connecting cilia $(\rightarrow)$ and their associated basal bodies are shown.

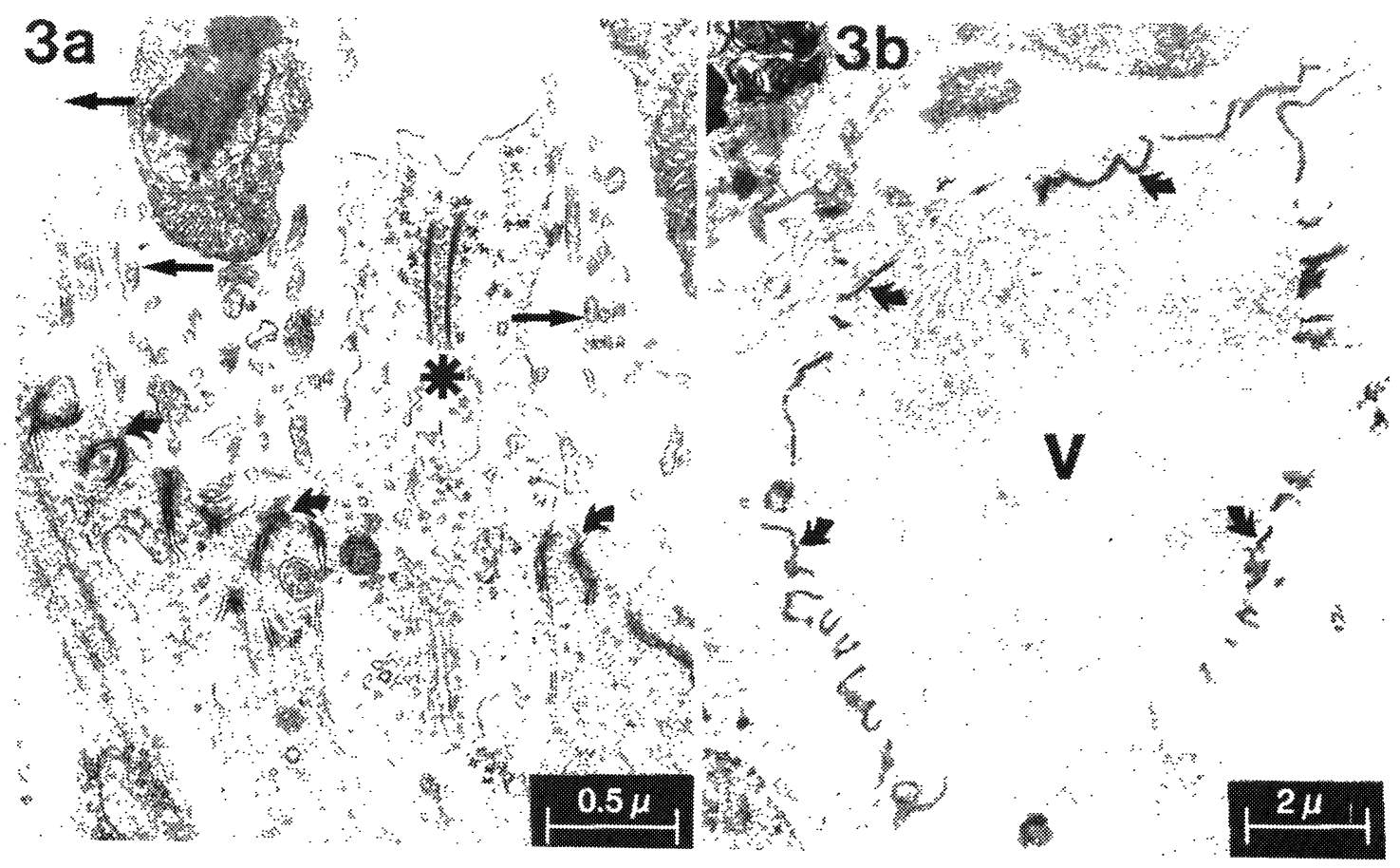

Fig. 3: (a) Müller glia microvilli $(\rightarrow)$ are shown projecting into the center of a rosette. A photoreceptor inner segment is also visible (*). (b) In extreme cases, the center of the rosette appeared to consist of microvilli only (V). In both $\mathbf{a}$ and $\mathbf{b}$, a distinct outer limiting membrane made up of a band of junctions is seen ( $\boldsymbol{\Psi}$ ). 


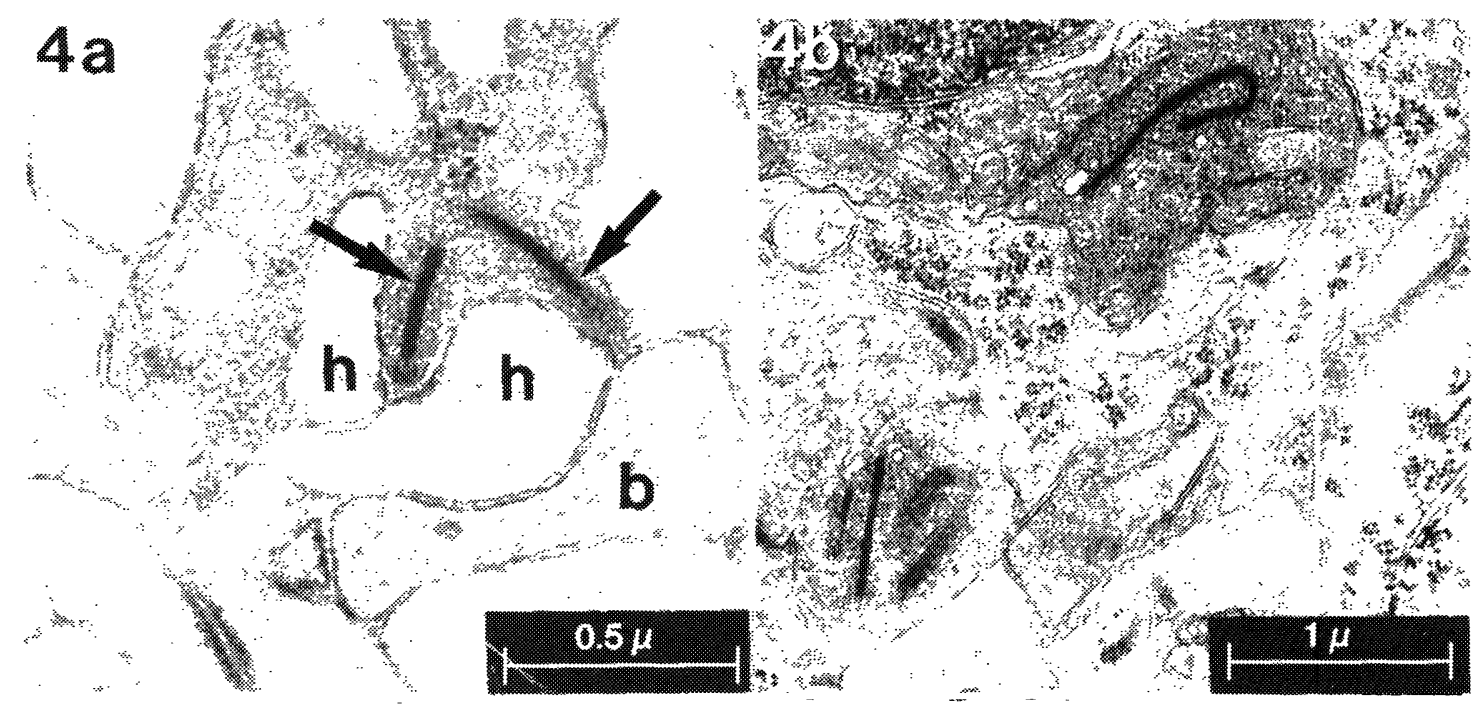

Fig. 4: Electron micrographs of synaptic features common within outer plexiform regions of retinal transplants. (a) Shows a photoreceptor synaptic terminal with several characteristic synaptic ribbons $(\rightarrow)$, with postsynaptic horizontal (h) and bipolar (b) cell processes arranged in a typical triadic configuration. (b) Especially in epiretinal grafts, photoreceptor synaptic terminals occasionally exhibited synaptic ribbons without any direct association with the cell membrane or any postsynaptic processes.

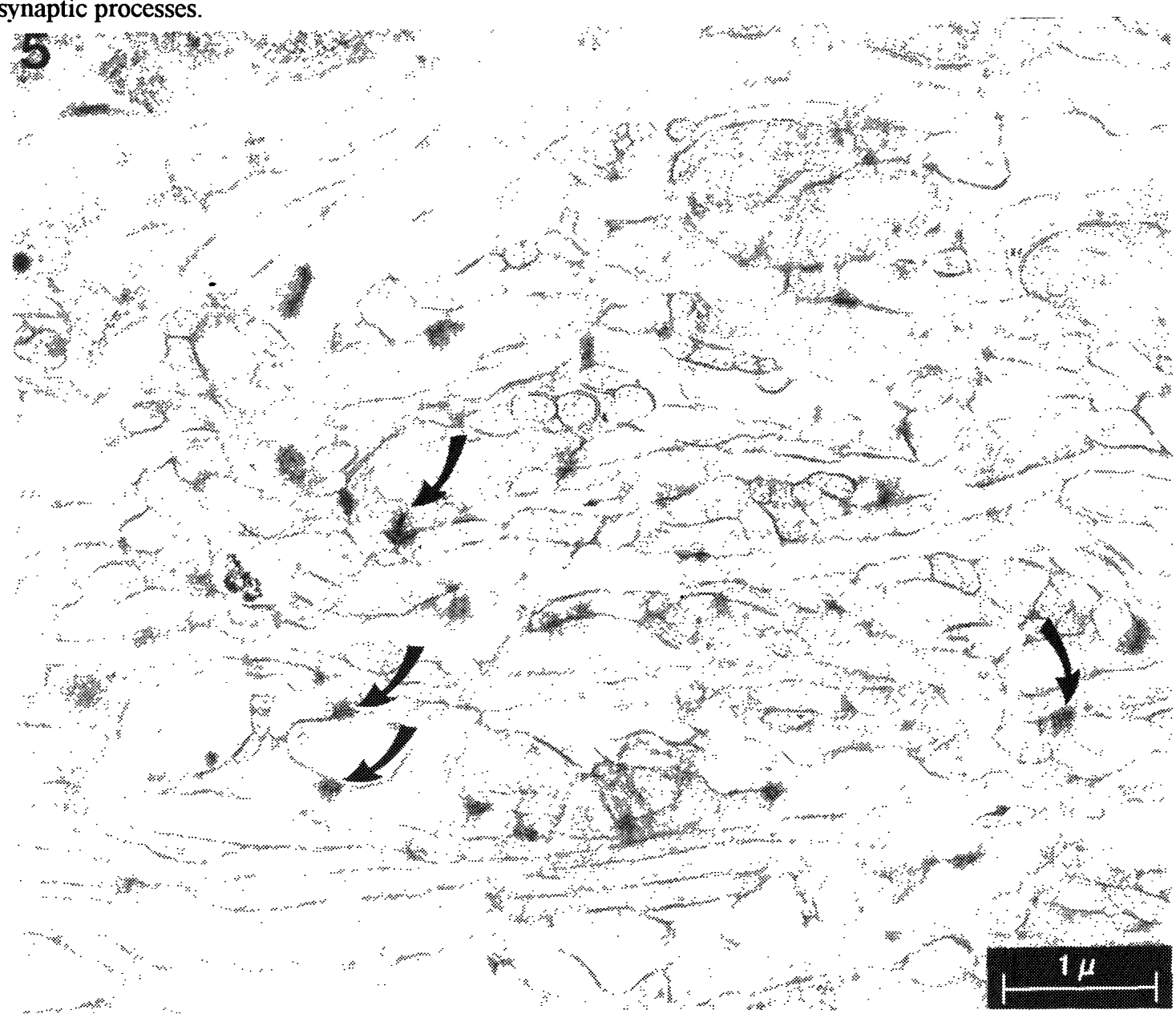

Fig. 5: A low magnification electron micrograph showing a region corresponding to the inner plexiform layer. A relatively high synaptic density, which was consistent from region to region, is apparent. Some representative synaptic contacts are indicated (ע). 


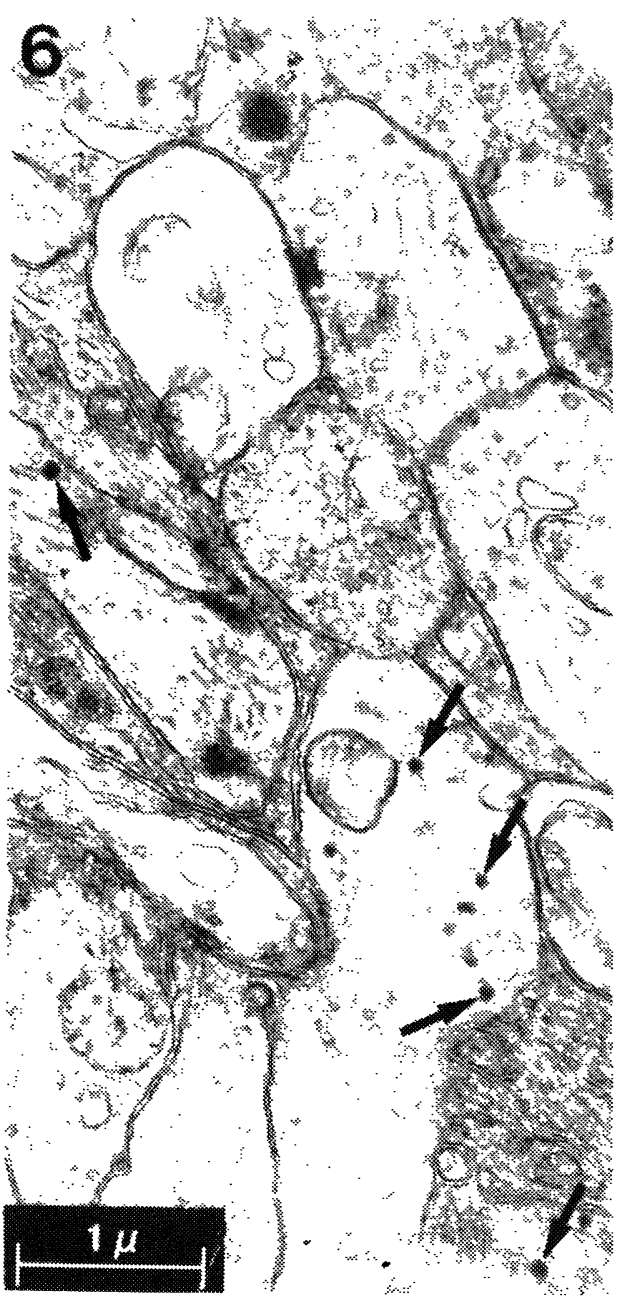

Fig. 6: Electron micrograph from an inner plexiform region of a subretinal graft. Most, but not all synaptic terminals contained conventional synaptic vesicles. As is shown here, small and large densecored vesicles could be seen $(\rightarrow)$.
Gap junctions between an amacrine cell process and a dissimilar but unidentifiable process have also been noted (Figure 9b).

\section{Epiretinal transplants}

Regions resembling the outer and inner plexiform layers were somewhat difficult to find in this transplant type. Although rosettes were common, their borders tended to be poorly delineated. Occasionally, photoreceptor terminals appeared in general neuropil areas which also contained amacrine cell synaptic contacts. When present, these photoreceptor terminals rarely contained clearly defined postsynaptic elements. Furthermore, the synaptic ribbons in epiretinal transplants sometimes appeared to be condensed, abnormally folded, or as two or three segments lying next to each other. They often showed no direct relationship with the cell membrane. Within rosette cores, photoreceptor inner and outer segments were found only at a low density and were poorly developed. The cores were frequently densely filled with microvilli from Müller cells radiating out of a well-defined outer limiting membrane.

Contrasting with observations on subretinal transplants, regions of the inner plexiform layer type tended to be quite variable in epiretinal transplants, with poor structural integrity in many regions. Many amacrine cell terminals exhibited only an electrontranslucent cytoplasm with a low density of synaptic vesicles. Synapses made by these terminals often displayed only a few synaptic vesicles (Figure 10). Intermixed with such terminal "ghosts", amacrine cell terminals with a relatively normal appearance, containing a good complement of synaptic vesicles, usually of the small type, could be found. Occasional large dense-cored vesicles were also observed. There was also a significant variability in the morphology of bipolar cell terminals, some being relatively normal, whereas many showed monadic arrangements or ribbons not associated with other synaptic structures.

\section{DISCUSSION}

The observations reported in this study show that synapses form in large numbers in regions analogous to the inner and outer plexiform layers. This conclusion correlates well with results obtained in a study with human to rat xenotransplants $/ 17,18 /$ and synapses have also been noted in other electron microscopic studies of retinal cell transplants (see, e.g., /11/). Most synaptic contacts appear normal in terms of their morphological characteristics. This is an important observation, because it suggests a high degree of organization within the transplants, even 


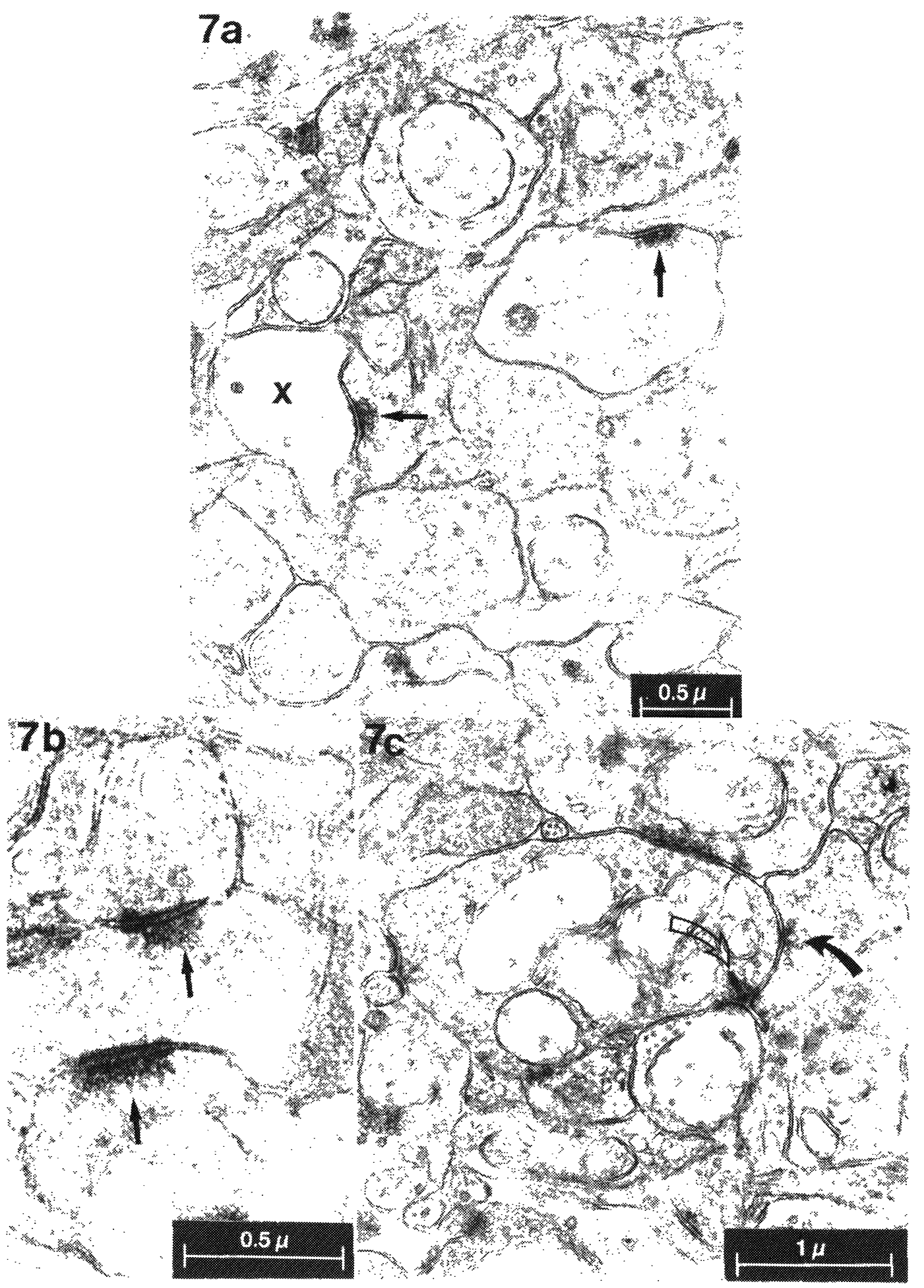

7: Electron micrographs from an inner plexiform region of a subretinal graft. (a) Shows two examples of conventional amacrine cell synapses $(\rightarrow)$ frequently found in inner plexiform regions of retinal transplants. Note the presynaptic clusters of synaptic vesicles as well as the pre- and postsynaptic membrane thickenings. The postsynaptic targets of these amacrine cell synapses are another amacrine cell process and a process with insufficient structural components to make a positive identification (x). (b) Amacrine cell synapses arranged in a serial configuration were also common $(\rightarrow)$ ). As is shown in (c), amacrine cell processes also made contacts with $(\boldsymbol{y})$, and received input from ( $(\mathbf{})$, bipolar cell processes. 


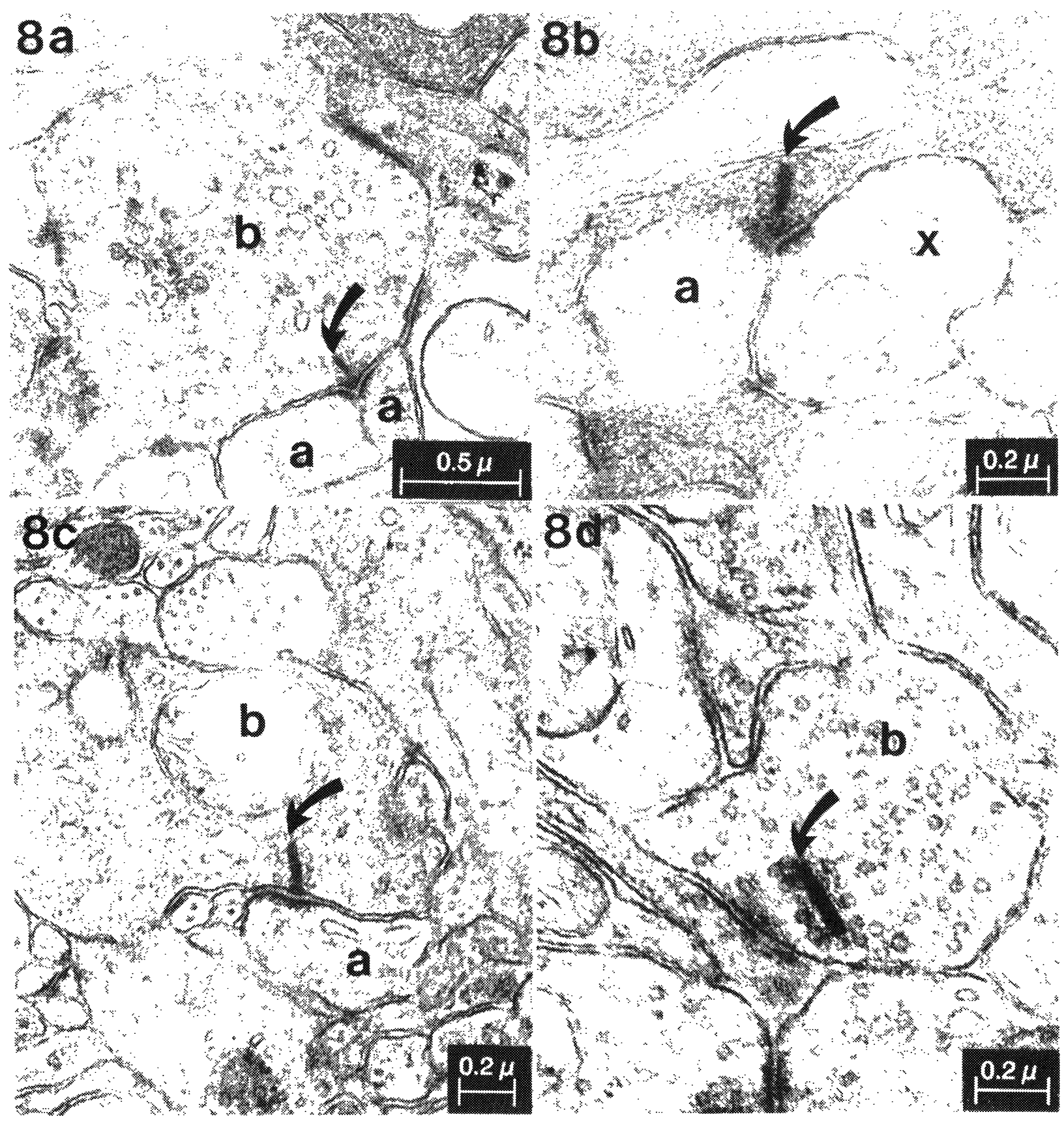

Fig. 8: Electron micrographs of bipolar cell processes within retinal cell transplants. (a) This micrograph shows a bipolar cell synaptic terminal (b), in an inner plexiform region of a graft, exhibiting a synaptic ribbon (ע). Both postsynaptic processes are of amacrine cell origin (a) in a typical dyadic arrangement. (b) Another bipolar cell terminal is shown with a characteristic synaptic ribbon ( $\boldsymbol{y})$. The two postsynaptic processes are dissimilar; one of which is of amacrine cell origin (a), whereas the other exhibits electron-lucent cytoplasm, microtubules and no synaptic vesicles (x). (c) A bipolar cell terminal (b) with a synaptic ribbon $(\boldsymbol{y})$ is shown making a monadic synapse onto an amacrine cell process (a). (d) An example is shown of a bipolar cell process (b) with a synaptic ribbon ( $\boldsymbol{y})$ not directly associated with the cell membrane or any postsynaptic process. 


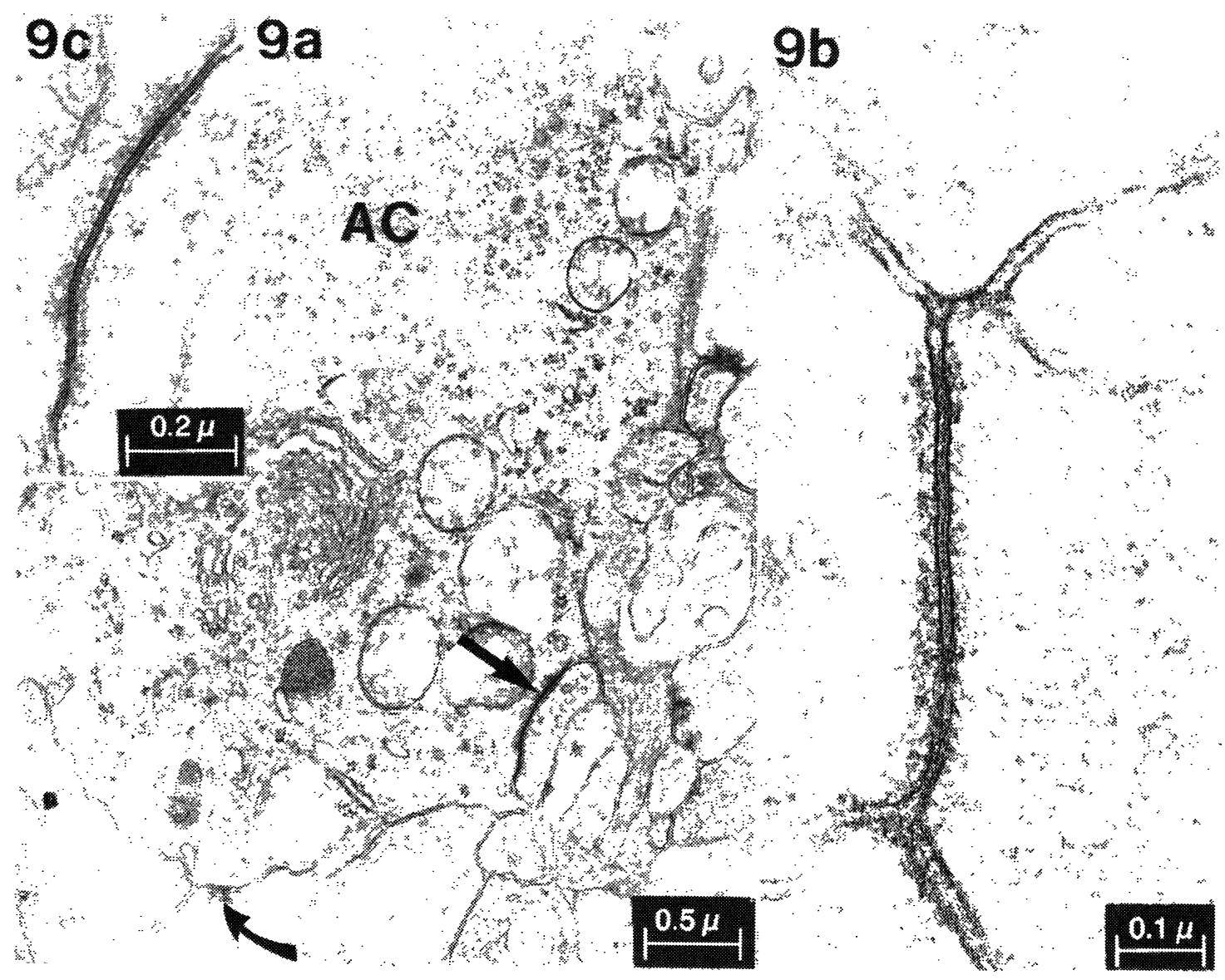

Fig. 9: Electron micrographs of electrical gap junctions found within inner plexiform regions of subretinal grafts. (a) An amacrine cell body (AC) is shown making a gap junction $(\rightarrow)$ with an amacrine cell process. Note the nucleus and other organelles characteristic of cell bodies. This cell body is also shown receiving input from an amacrine cell process via a conventional chemical synapse (y). The inset (c) shows details of the gap junction. Note the well aligned, fused membranes which are characteristic of gap junctions. (b) An example of a gap junction between an amacrine cell process and a dissimilar neuronal process is shown.

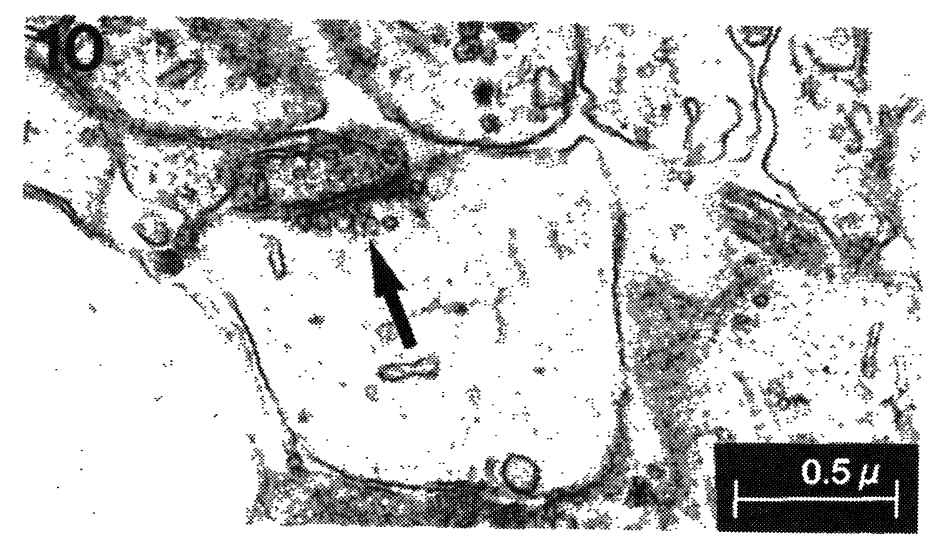

Iig. 10: Electron micrograph of an amacrine-to-amacrine cell synapse in an epiretinal transplant. Note the relatively few synaptic vesicles clustered at the presynaptic membrane $(\rightarrow)$ and the sparse nature of the cytoplasm. 
though they show rosettes and similar deviations from the normal retinal lamination.

At the time of transplantation (stage E15; see $125 /$ ), the rat retina is poorly developed. Most cells are still neuroblastic, but synapses in the inner plexiform layer have begun to form. There is no outer plexiform layer yet. Photoreceptor outer segments do not begin to develop until the fifth postnatal day (see /8/). The observation of well developed cells with different types of synapses shows that significant growth and differentiation of the transplanted cells had taken place, despite the disruption of tissue structure that occurs during transplantation as well as the foreign environment in the host eye. Not only did all major synaptic types develop, but there were also signs of more advanced circuitry in the form of reciprocal synapses involving two amacrine cell processes or a bipolar and an amacrine cell process. However, some regions contained less well developed cells. The reason for this heterogeneity is not clear. Cells from peripheral parts of the retina are known to differentiate significantly later than cells from the central regions. Donor tissue contained cells from both the central and peripheral parts of the retina. However, the developmental difference between peripheral and central retina is less than one week in the rat, and it therefore appears uncertain whether this alone could account for the observed difference in different parts of the transplant after a month or more of development. It is conceivable that the foreign milieu of the host retina slows down development.

Different retinal cell types are identified on the basis of specific characteristics seen in the electron microscope. This identification is easier for some cell types than for others. Each portion of highly polarized photoreceptors has a very characteristic appearance and is therefore usually easy to identify. The presence of horizontal cells can be inferred from the presence of processes with characteristic location and structure in the invaginations of the tetrad photoreceptor synaptic terminals. Bipolar cell processes can be similarly identified, and their synaptic terminals in regions corresponding to the inner plexiform layer can be identified via the characteristic synaptic ribbon they contain and the distinctive organization of the postsynaptic dyad.
The foremost characteristic of an amacrine cell is its synapse of the so-called conventional type, and numerous such synapses have been observed.

Ganglion cells or their processes have not been observed with certainty in these retinal cell transplants. However, in this study, process profiles have been seen that would have been classified as likely to belong to ganglion cells in a normal retina. For instance, it was commonly observed that the bipolar cell dyads had postsynaptic processes of two types, one of which was an amacrine cell process whereas the other was different, with more electron-lucent cytoplasm containing microtubules and no synaptic vesicles. Such profiles would, in normal retinas, be classified as ganglion cell processes. However without other supporting evidence, such an identification cannot be made. It may be noted that most degenerative retinal diseases affect primarily the outer retina, leaving the ganglion cells relatively intact. It is therefore not a necessary requirement to have ganglion cells develop in a retinal cell transplant in order to obtain connections between the transplanted photoreceptor cells and the brain of a host animal with a tapetoretinal degeneration.

It has previously been shown that the lamination is better developed in subretinal transplants than in epiretinal ones $/ 3 /$. Similar differences were seen in this study.

Gap junctions have long been recognized between horizontal cells in the retinal from fish and other cold-blooded vertebrates. More recently, gap junctions between amacrine cell processes and between amacrine cell processes and bipolar cell terminals have been described in both mammalian and non-mammalian retinas. It has been shown beyond doubt that gap junctions are present in both the inner and outer plexiform layers in significant numbers in all species examined /10,23,24,34-36/ and it is now accepted that they are a general feature of retinal circuitry.

Gap junctions have not been noted previously in other transplants. The reason may be that they are relatively difficult to discern and less common than chemical-type synapses. There may also be species differences, but this appears less likely, because we have now seen them also in rabbit-to-rabbit retinal cell transplants (Zucker, Bergström and Adolph, 
unpublished observations). The observation of gap junctions between amacrine cells in retinal cell transplants in addition to the chemical synapses is an indication that many of the neuronal circuits found in normal retinas had developed in the transplants.

Extensive processing of visual signals starts in the retina which results in a highly coded message that is transmitted by the optic nerve via many parallel channels. With the appearance of both photoreceptors with reasonably well developed outer segments and the other cell types and synapses seen in the normal retina, it appears that not only light reception and transduction but also some degree of signal processing should be possible in the transplants. Electrophysiological studies /1,2/ have shown that this is indeed likely.

\section{ACKNOWLEDGEMENTS}

This study was supported by the Retinal Transplant Program of the Schepens Eye Research Institute and by grants from NIH (EY07552 to CLZ), the Swedish Medical Research Council (project 14X 2321), the Swedish Institute, the Segerfalk Foundation, the Crafoord Foundation, the $\mathrm{H}$ and $\mathrm{L}$ Nilssons Stiftelse, the $\mathrm{T}$ and $\mathrm{R}$ Söderberg Foundation, Dr. S. Williams, and the Faculty of Medicine at the University of Lund. The technical assistance of Nike Beckmann is gratefully acknowledged.

\section{REFERENCES}

1. Adolph AR, Zucker CL, Ehinger B, Bergström A. Functional properties of subretinal transplants in rabbit. J Neural Transplant Plast 1992; 3: 281-282.

2. Adolph AR, Zucker CL, Ehinger B, Bergström A. Function and structure in isolated subretinal transplants. Invest Ophthalmol Vis Sci 1993; 34: 1096.

3. Aramant R, Seiler M. Cryopreservation and transplantation of immature rat retina into adult rat retina. Dev Brain Res 1991; 54: 1-20.

4. Aramant $R$, Seiler $M$, Ehinger $B$, Bergström A, Adolph AR, Turner JE. Neuronal markers in rat retinal grafts. Dev Brain Res 1990; 43: 47-61.

5. Aramant $R$, Seiler $M$, Ehinger $B$, Bergström A, Gustavii B, Brundin P, Adolph AR. Transplantation of human embryonic retina to adult rat retina. Restor Neurol Neurosci 1990; 2: 9-22.

6. Aramant R, Seiler M, Turner JE. Donor age influences on the success of retinal grafts to adult rat retina. Invest Ophthalmol Vis Sci 1988; 29: 498-503.

7. Aramant $R$, Turner JE. Cross-species grafting of embryonic mouse and grafting of older postnatal rat retinas into the lesioned adult rat eye: the importance of cyclosporin A for survival. Brain Res 1988; 469: 303-307.

8. Barnstable CJ. Immunological studies of the diversity and development of the mammalian visual system. Immunol Rev 1987; 100: 47-78.

9. Bergström A, Ehinger B, Wilke K, Zucker C, Adolph A, Aramant R, Seiler M. Transplantation of embryonic retina to the subretinal space in rabbits. Exp Eye Res 1992: 55: 29-37.

10. Daw NW, Jensen RJ, Brunken WJ. Rod pathways in mammalian retinae. Trends Neurosci 1990; 13: 110115.

11. del Cerro M. Retinal transplants. Prog Retinal Res 1990; 9: 229-272.

12. del Cerro M, Ison JR, Bowen GP, Lazar E, del Cerro C. Intraretinal grafting restores visual function in light-blinded rats. Neuro Report 1991; 2: 529-532.

13. del Cerro M. Kordower JH, Lazer E, Grover DA, del Cerro C. Photoreceptor differentiation in retinal xenografts of fetal monkey retina. Brain Res 1992; 574: $1-8$.

14. del Cerro M, Notter MF, del Cerro C, Wiegand SJ, Grover DA, Lazar E. Intraretinal transplantation for rod-cell replacement in light-damaged retinas. J Neural Transplant 1989; 1: 1-10.

15. del Cerro $M$, Notter MF, Wiegand SJ, Jiang LQ, del Cerro C. Intraretinal transplantation of fluorescently labeled retinal cell suspensions. Neurosci Lett 1988; 92: 21-26.

16. Du J, Gouras P, Kjeldbye H, Kwun R, Lopez R. Monitoring photoreceptor transplants with nuclear and cytoplasmatic markers. Exp Neurol 1992; 115: 79-86.

17. Ehinger B, Bergström A, Seiler M, Aramant RB, Zucker CL, Gustavii B, Adolph AR. Ultrastructure of human retinal cell transplants with long survival times in rats. Exp Eye Res 1991; 53: 447-460.

18. Ehinger B, Zucker C, Bergström A, Seiler M, Aramant R, Adolph A. Electron microscopy of human first trimester and rat mid-term retinal cell transplants with long development time. Neuro-ophthalmology 1992; 12: 103-114.

19. Ehinger $B$, Zucker CL, Bergström A, Seiler $M$, Aramant RB, Gustavii B, Adolph A. Ultrastructure of long term retinal cell transplants to rat retina. In: Anderson RR, et al., Retinal Degenerations. Boca Raton: CRC Press, Inc., 1991: 263-275.

20. Gouras P, Du J, Kjeldbye H, Yamamoto S, Zack DJ. Reconstruction of degenerate rd mouse retina by 
transplantation of transgenic photoreceptors. Invest Ophthalmol Vis Sci 1992; 33: 2579-2586.

21. Gouras P, Jing D, Kjeldbye H, Kwun R, Lopez R, Zack DJ. Transplanted photoreceptors identified in dystrophic mouse retina by a transgenic reporter gene. Invest Ophthalmol Vis Sci 1991; 32: 3167-3174.

22. Gouras P, Lopez R, Du J, Gelanze M, Kwun R, Brittis $M$, Kjeldbye $H$. Transplantation of retinal cells. Neuroophthalmology 1990; 10: 165-176.

23. Hampson EC, Vaney DI, Weiler R. Dopaminergic modulation of gap junction permeability between amacrine cells in mammalian retina. J Neurosci 1992; 12: 4911-4922.

24. Kolb H. Cuenca N, Dekorver L. Postembedding immunocytochemistry for GABA and glycine reveals the synaptic relationships of the dopaminergic amacrine cell of the cat retina. J Comp Neurol 1991; 310: 267-284.

25. Perry VH, Walker M. Morphology of cells in the ganglion cell layer during development of the rat retina. Proc R Soc Lond (Biol) 1980; 208: 433-445.

26. Schuschereba ST, Silverman MS. Retinal cell and photoreceptor transplantation between adult New Zealand red rabbit retinas. Exp Neurol 1992; 115: 9599.

27. Seiler M, Aramant RB, Ehinger B, Adolph AR. Transplantation of embryonic retina to adult retina in rabbits. Exp Eye Res 1990; 51: 225-228.

28. Seiler $M$, Aramant $R$, Ehinger $B$, Bergström A, Adolph AR. Characteristics of embryonic retina transplanted to rat and rabbit retina. Neuroophthalmology 1991; 11: 263-279.

29. Seiler M, Turner JE. The activities of host and graft glial cells following retinal transplantation into the lesioned adult rat eye: developmental expression of glial markers. Brain Res 1988; 471: 111-122.

30. Silverman MS, Hughes SE. Photoreceptor transplantation in inherited and environmentally induced retinal degeneration: anatomy, immunohistochemistry and function. Prog Clin Biol Res 1989; 314: 687-704.

31. Silverman MS, Hughes SE. Transplantation of photoreceptors to ligh-damaged retina. Invest Ophthalmol Vis Sci 1989; 30: 1684-1690.

32. Silverman MS, Hughes SE, Valentino TL, Liu Y. Photoreceptor transplantation: Anatomic, electrophysiologic, and behavioral evidence for the functional reconstruction of retinas lacking photoreceptors. Exp Neurol 1992; 115: 87-94.

33. Turner JE, Blair JR. Newborn rat retinal cells transplanted into a retinal lesion site in adult host eyes. Brain Res 1986; 391: 91-104.

34. Vaney DE, Young HM, Gynther IC. The rod circuit in the rabbit retina. Vis Neurosci 1991; 7: 141-154.

35. Vaney DI, Gynther IC, Young HM. Rod-signal interneurons in the rabbit retina: 2 . All amacrine cells. J Comp Neurol 1991; 310: 154-169.

36. Young HM, Vaney DI. Rod-signal interneurons in the rabbit retina: 1. Rod bipolar cells. J Comp Neurol 1991; 310: 139-153.

37. Zucker CL, Seiler M, Aramant R, Adolph AR. Microcircuitry of retinal transplants: ultrastructural observations. Soc Neurosci Abstr 1989; 15: 1367.

38. Zucker CL, Seiler M, Aramant R, Adolph AR. Ultrastructural microcircuitry of rat retinal transplants. Proc Int Soc Eye Res 1990; VI: 51. 

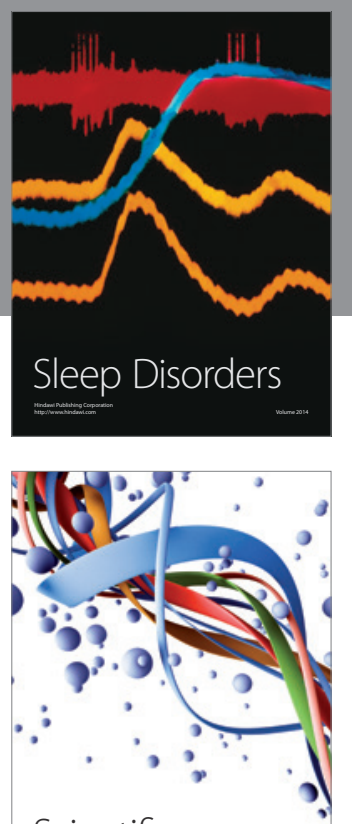

Scientifica
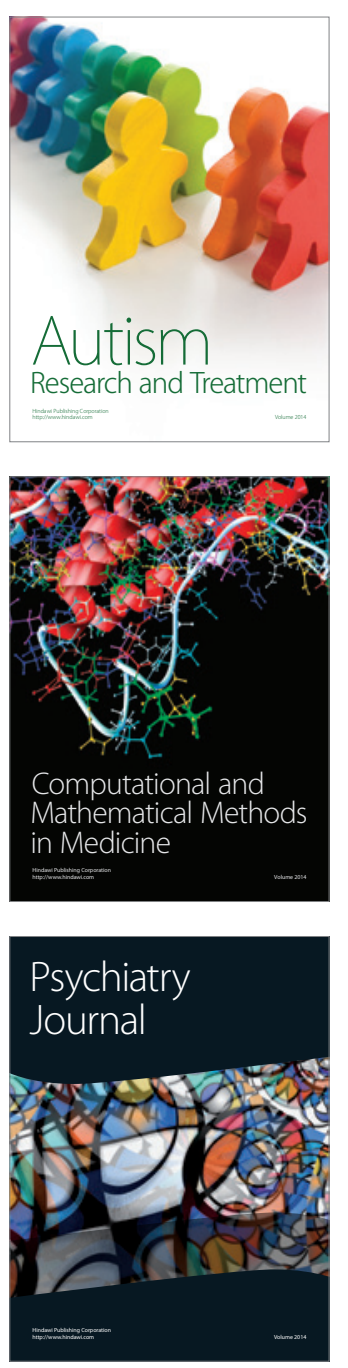
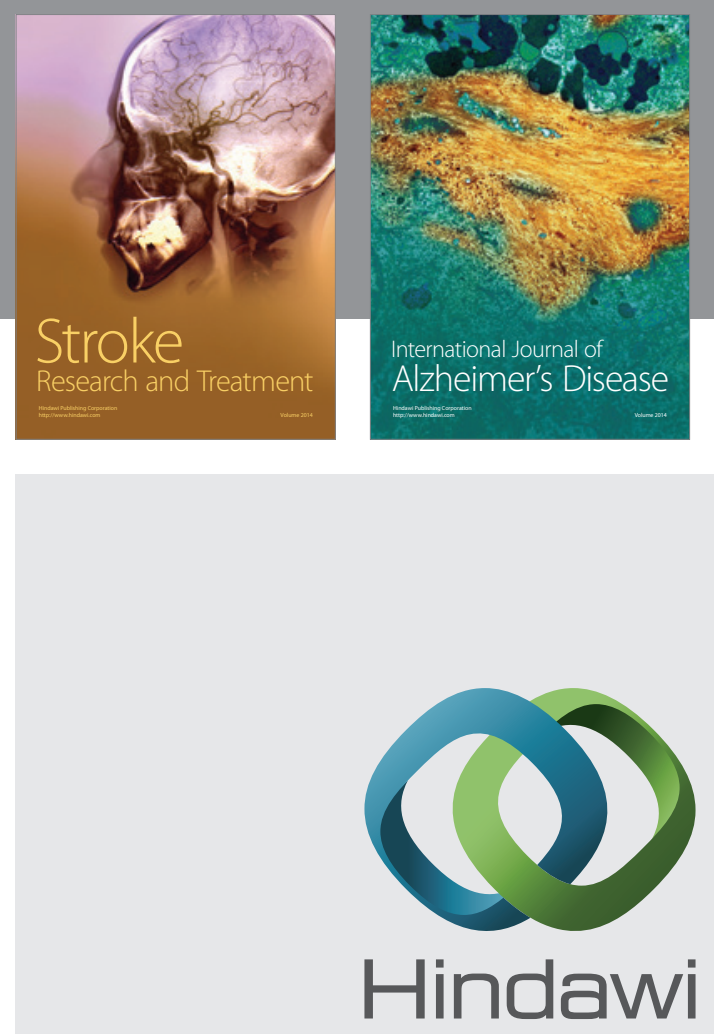

Submit your manuscripts at

http://www.hindawi.com
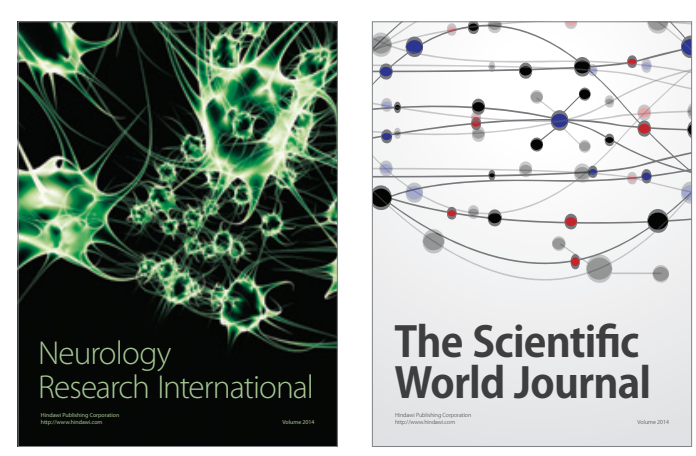

The Scientific World Journal

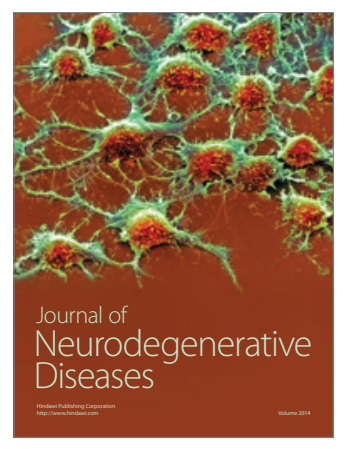

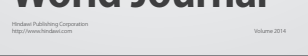

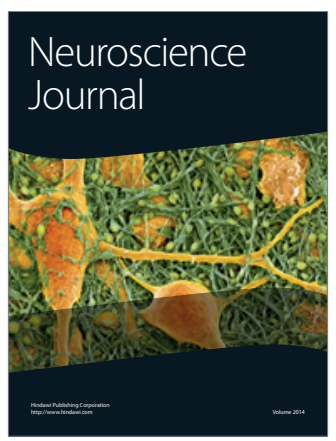

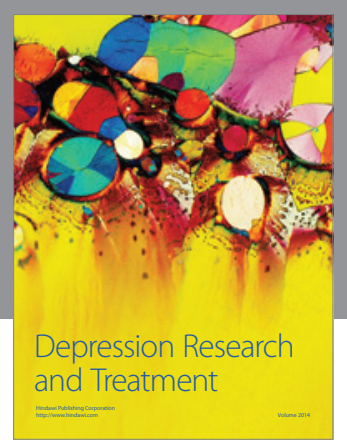
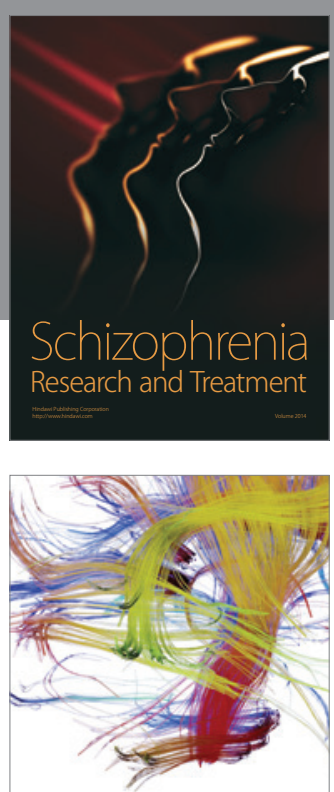

Brain Science

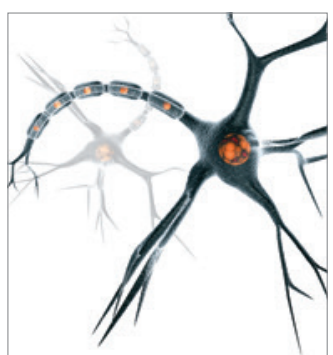

Neural Plasticity
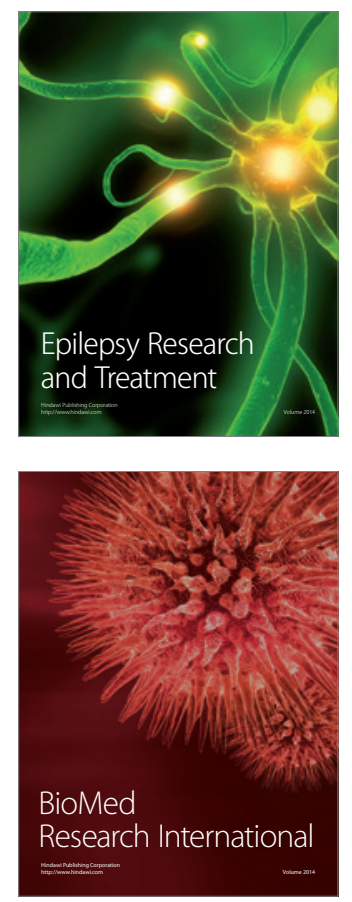

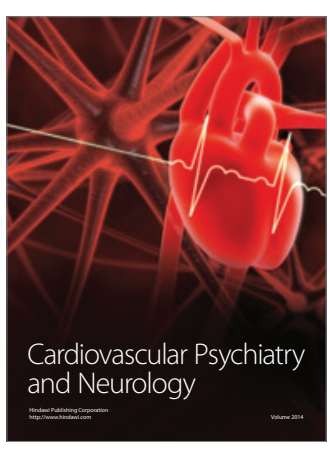

Parkinson's

Disease
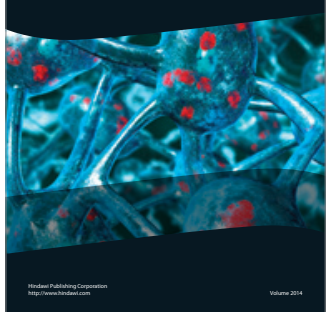